
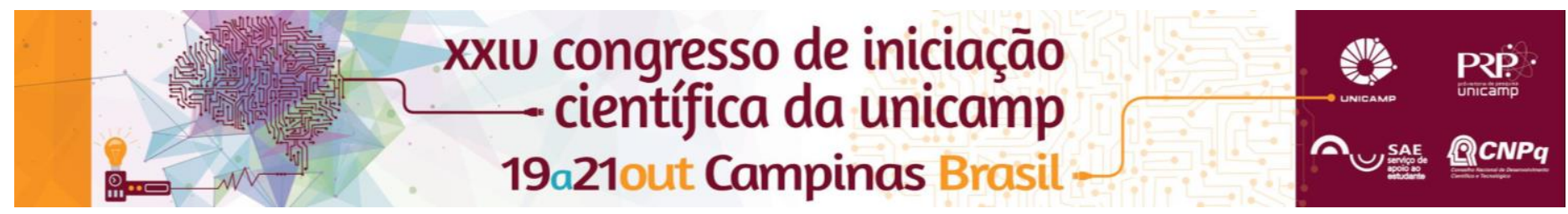

\title{
Estudo da estrutura eletrônica e atômica das superfícies de fósforo negro funcionalizado
}

\author{
Kelvin Erneque Santos, Abner de Siervo
}

\begin{abstract}
Resumo
Nesse trabalho estudamos a estabilidade térmica e funcionalização por oxigênio e ferro da superfície de uma amostra de cristal de fósforo preto (BP - black phosphorus). A estrutura eletrônica destas amostras foi investigada usando espectroscopia de fotoelétrons excitados por raios X (XPS). Os resultados mostram que o tratamento térmico do BP induz uma modificação em sua estrutura (provavelmente uma transição de fase para o fósforo vermelho). Na oxidação foram observadas mudanças tênues nas componentes das quatro tentativas de oxidação, de modo que não é possível fazer afirmações sobre possíveis mudanças químicas na amostra. Os resultados indicam certa estabilidade química do BP à oxidação. Além disso, na funcionalização da superfície com Fe, os dados de XPS indicam que foram formadas ligações P-Fe durante o crescimento de Fe sobre BP.
\end{abstract}

\section{Palavras-chave:}

Fósforo negro, fosforeno, Estrutura eletrônica de superfície.

\section{Introdução}

Nos últimos anos os cristais bidimensionais, despertaram grande interesse científico e tecnológico devido às propriedades físicas que possibilitam diversas aplicações destes materiais. Recentemente renasceu o interesse em uma fase cristalina de fósforo, o black phosphorus $(\mathrm{BP})$, que também é um material em camadas. BP é uma fase estável do fósforo à temperatura ambiente e a pressão atmosférica, formado por bicamadas enrugadas [1]. Os átomos de fósforo nas bicamadas estão ligados covalentemente enquanto a interação entre bicamadas é fraca, tipo van der Waals. O BP tem o valor de seu gap variado, indo de $0.3 \mathrm{eV}$, no caso de várias bicamadas, até $1.8 \mathrm{eV}$ para camada simples, o fosforeno. Neste trabalho investigamos as mudanças químicas no BP e em sua superfície após a funcionalização do mesmo por oxigênio e por depósitos de ferro.

\section{Resultados e Discussão}

O cristal de BP foi clivado utilizando uma fita adesiva e as medidas de XPS foram realizadas no LNLS bem como microscopia STM nos laboratórios do grupo. Apresentamos os diversos experimentos realizados:

Estabilidade térmica do BP: Neste experimento verificamos o estágio inicial de uma transição de fase do BP para, provavelmente, o Fósforo Vermelho (RP). A estrutura eletrônica mostrou a coexistência de duas fases estruturais do BP. Também observamos esta indicação em imagem de microscopia de tunelamento de elétrons (STM) (vide-figura 1).

Oxidação da superfície do BP: As medidas de XPS indicaram certa estabilidade da superfície à oxidação por oxigênio molecular, particularmente para oxidações à temperatura ambiente em regimes de baixa e alta pressão parcial de oxigênio. No processo de oxidação do $\mathrm{BP}$, podemos observar que ocorreu um deslocamento dos picos e uma suave deformação da forma de linha da amostra limpa em comparação com as oxidações, sendo que estes espectros não necessariamente indicam a formação de uma fase funcionalizada com formação de ligações P-O (figura não apresentada aqui).
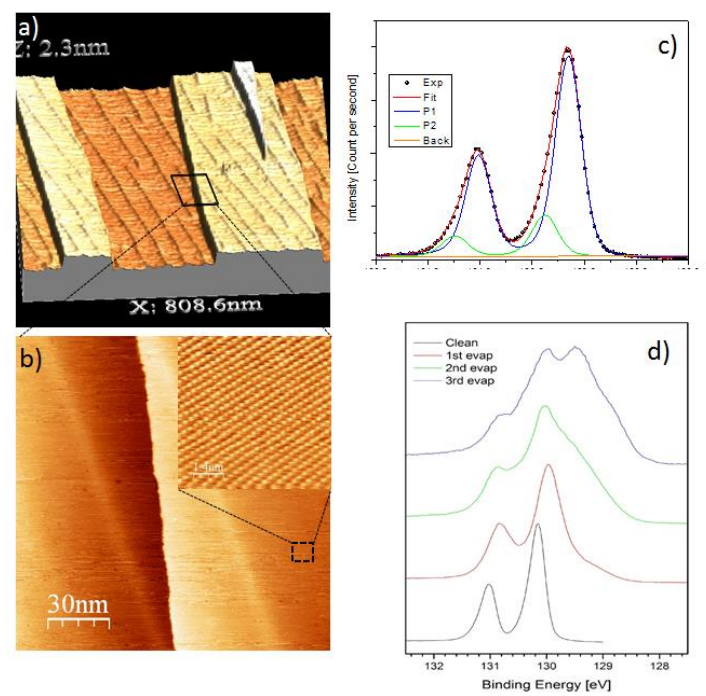

Figura 1- (a) e (b) Imagens STM do BP após tratamento térmico. (c) XPS da amostra após tratamento térmico indicando a coexistência de duas fases (P1 e P2) para os picos de fotoemissão do P 2p. (d) XPS do $P 2 p$ como função da cobertura de $F e$, indicando a formação de ligações P-Fe.

Crescimento de filmes de ferro sobre o BP: Também procuramos verificar como o BP interage com metais reativos e com propriedades magnéticas, tal como o $\mathrm{Fe}$. Verificou-se que $0 \mathrm{Fe}$ interage fortemente com a superfície do BP formando ligações P-Fe (vide figura 1d)

\section{Conclusão}

Através do estudo da estrutura eletrônica por fotoemissão e por imagens de STM verificou-se a estabilidade térmica e funcionalização do BP por $\mathrm{O}_{2}$ e Fe.

\section{Agradecimentos}

Agradeço o Grupo de Físíca de Superfíces do IFGW pelo suporte e em especial ao meu orientador pela paciência e instrução no laboratório. Também ao CNPq e à UNICAMP pelo financiamento.

[1] Luis Henrique de Lima, Lucas Barreto, Richard Landers, Abner de Siervo, Physical Review B 93, 035448 (2016). 